\title{
Design of Wearable Textile based Microstrip-Line-Fed Antenna with Defected Ground Structure
}

\author{
Priyesh Jaiswal \\ Department of Electronics Engineering \\ University Institute of Technology, Barkatullah \\ University, Bhopal
}

\author{
Poonam Sinha, $\mathrm{PhD}$ \\ Department of Electronics Engineering \\ University Institute of Technology, Barkatullah \\ University, Bhopal
}

\begin{abstract}
By using the concept of defect ground structure (DGS) plane, a microstrip antenna is designed for $\mathrm{C}$ and $\mathrm{S}$ Band applications. The antenna is designed on polyester substrate with operating frequency $3 \mathrm{GHz}$. Defected ground structure is used to enhance the impedance bandwidth. A meander shape is integrated on the ground plane and corners are truncated. A $50 \Omega$ microstrip feed line which behaves like a tuning stub, is used to excite the proposed antenna. The variation in the length of tuning stub affects the reflection coefficient of the proposed antenna and hence controls the return loss level as well as improves other parameters. The simulation of proposed antenna is done on IE3D tool and measure characteristics of fabricated antenna.
\end{abstract}

\section{Keywords}

Microstrip patch antenna (MPA), microstrip feed line, Defect ground structure (DGS), tuning stub.

\section{INTRODUCTION}

Wireless communication systems become more and more popular day by day, which results to develop an interest to work on improvement of antenna performances. As we already knowthat microstrip antenna is advantageous over conventional microwave antennas and therefore used in various fields such as global positioning system applications, mobile and satellite communication application, radar application and telemedicine application [1]. There are many advantages of MPA over conventional microwave antenna such as light weight, thin profile, dual frequency and dual polarization, easy fabrication etc. However antenna has it's inherently shortcomings such as narrow impedance bandwidth, low gain and efficiency. Much intensive research has been done in recent years to develop bandwidth enhancement as well as to improve other parameters.

Microstrip patch antennas with the concept of defect ground structure are considered for improving the impedance bandwidth of the designed antenna [2-5]. Microstrip antenna with circular defect is considered for cross- polarization suppuration and bandwidth enhancement up to $56.6 \%$ [2]. Defect ground structures are reported to suppress the crosspolarization (XP) level to a larger extent [3]. Dual band with circular polarization in lower and upper band is achieved by using truncated defect ground structure [4]. A printed wide slot antenna with a rotated slot which is fed by $50 \Omega$ microstrip feed line is considered for enhancement of impedance bandwidth up to $48.8 \%$ [5]. For efficient results accurate feeding is required and for that resistance as the function of feed location and frequency is estimated accurately [6].

In this paper MPA is proposed with a meandered ground plane and truncated corners. A $50-\Omega$ Microstrip feed line is used to feed the proposed structure. The microstrip feed line which comes under the meander slot isconsidered as a tuning stub for the designed structure.

\section{THE DEFECTED GROUND STRUCTURE (DGS)}

Microstrip antennas with slot of any geometry integrated on the ground planeare defined as defect ground structures. The slots integrated on the ground plane are considered to improve thebandwidth of antenna to a great extent but the gain reduces due to the fact that slots are bidirectional. Different slot establish the different radiations pattern corresponding to its operating frequency.These types of antennas are also termed as slot antennas.

\section{DESIGNING AND CONFIGURATION OF MPA}

A meander slot is designed in the ground plane with four truncated corner and 50- $\Omega$ Microstrip line of dimension $w \times \operatorname{Lml}(w i d t h$ " $w$ " and length "Lml") is placed on the other side of the substratewhich is used for feeding the structure.The work is based on effective values of polyester substrate with operating frequency $3 \mathrm{GHz}$.

Fig. 1 and fig. 2 shows the back view and front view of the designed structure respectively.

\subsection{Designing of the Ground plane: -}

Thelength $(\mathrm{Lg})$ and width $(\mathrm{Wg})$ can be expressed as

$\mathrm{Lg}=\mathrm{L}+6 \mathrm{~h}$

$\mathrm{Wg}=\mathrm{W}+6 \mathrm{~h}$

Where " $h$ " represent the height of the dielectric constant of the substrate. "L" and "W" are the length and width (in $\mathrm{mm}$ ) of the microstrip patch respectively.

$\mathrm{W}$ and $\mathrm{L}$ are calculated as [1]

$W=\frac{1}{2 f_{r} \sqrt{\mu_{o} \varepsilon_{o}}} \sqrt{\frac{2}{\varepsilon_{r}+1}}(3)$

$\mathrm{L}=\mathrm{L}_{\mathrm{e}}-2 \Delta \mathrm{L}$ 


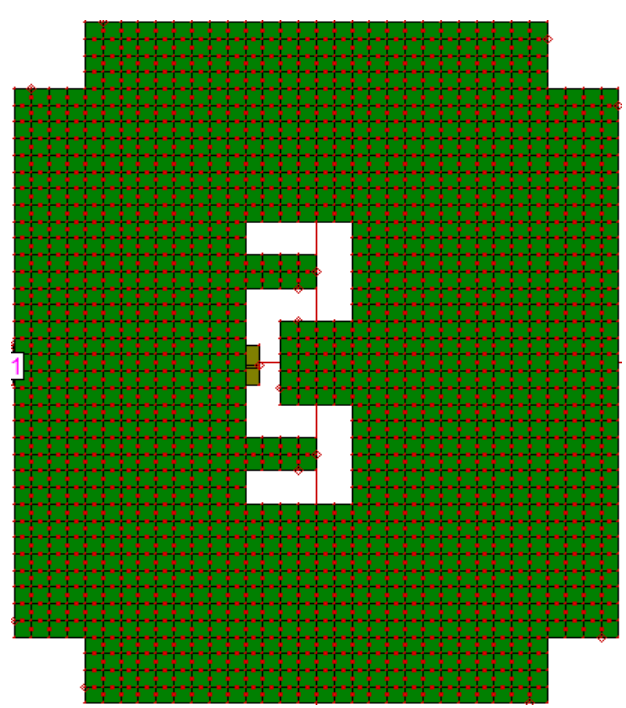

Fig 1 : Back view of proposed antenna

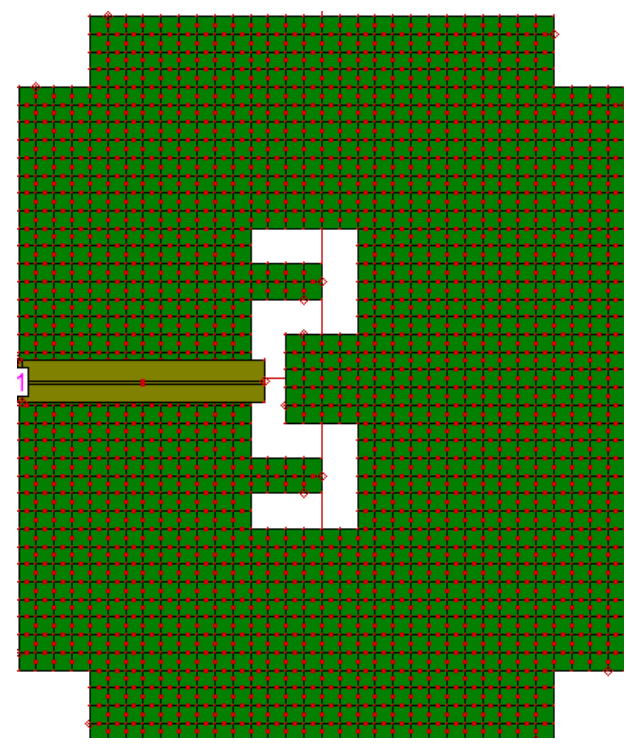

Fig 2: Front view of proposed antenna

Where, Leis the effective length and $\Delta \mathrm{L}$ is the extended Length of the patch and are expressed in equation (5), (6) and (7).

$$
\begin{aligned}
& L_{e}=\frac{c}{2 f_{o} \sqrt{\varepsilon_{e f f}}}(5) \\
& \Delta L=0.412 h \frac{\left(\varepsilon_{e f f}+0.3\right)\left(\frac{w}{h}+0.2664\right)}{\left(\varepsilon_{e f f}-0.258\right)\left(\frac{w}{h}+0.8\right)} \\
& \varepsilon_{e f f}=\frac{\varepsilon_{r}+1}{2}+\frac{\varepsilon_{r}-1}{2} \sqrt{\frac{1}{1+12 \frac{h}{w}}}(7)
\end{aligned}
$$

Where "c"represents the speed of light in free space and "ceff" represents the effective dielectric constant of the substrate. The ground planedimensionslength " $\mathrm{Lg}$ " and width "Wg" are calculated as $33.57 \mathrm{~mm}$ and $40.029 \mathrm{~mm}$ respectively. The truncated corners are of dimension 3.92 $\mathrm{mm} * 3.92 \mathrm{~mm}$.

\subsection{Designing of the Microstrip Line: -}

The width "w" of the Microstrip line can be calculated as [7]

$$
\begin{aligned}
& \frac{w}{h} \\
& =\left\{\begin{array}{ll}
\frac{8 e^{A}}{e^{2 A}-2} & \text { for } w / h<2 \\
\frac{2}{\pi}\left[\frac{\varepsilon_{r}-1}{2 \varepsilon_{r}}\left\{\ln (B-1)+0.39-\frac{0.61}{\varepsilon_{r}}\right\}\right.
\end{array}\right] \text { for } w / h>2
\end{aligned}
$$

Where,

$$
\begin{gathered}
A=\frac{Z_{o}}{60} \sqrt{\frac{\varepsilon_{r+1}}{2}+\frac{\varepsilon_{r}-1}{\varepsilon_{r}+1}\left(0.23+\frac{0.11}{\varepsilon_{r}}\right)} \\
B=\frac{377 \pi}{2 Z_{o} \sqrt{\varepsilon_{r}}}
\end{gathered}
$$

where "Z0" is the characteristic impedance of the microstrip line and is chosen as $50 \Omega$ for the design.

The length " $L_{m l}$ " of the Microstrip line can be expressed as

$L_{m l}=\frac{\lambda_{e f f}}{4}$

Where,

$\lambda_{\text {eff }}=\frac{c}{f \sqrt{\varepsilon_{e f f}}}$

The "w"and length "Lml" of microstrip feed line are calculated as $2.386 \mathrm{~mm}$ and $13.699 \mathrm{~mm}$ respectively.

\subsection{Designing of the Meander slot: -}

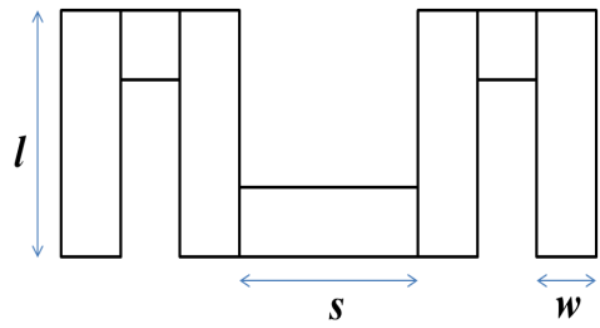

Figure 3. Geometry of designed slot $(l=5.5$ mm. $s=4.5 \mathrm{~mm}$ and $w=1.5 \mathrm{~mm}$.)

The meander slot is designed in the ground plane in such a way that the microstrip feed line which is designed on the other side of substrate is in the centre of slot and slot covers a small portion of the microstrip feed line as shown in fig. 1 and fig.2. The length Lmlof the microstrip feed line which is not including ground plane behaves as a matching stub for the slot. By varying the length of matching stub, the reflection coefficient of the antenna can be controlled and hence improves the return loss level. The internal gap of the meander slot is chosen as $1.5 \mathrm{~mm}$. Variation in the internal height of the slot tends to variation in the return loss level and impedance bandwidth. 


\section{DESIGN CONSIDERATION AND DISCUSSION OF RESULT}

The ground plane of dimension $33.57 \mathrm{~mm} * 40.029 \mathrm{~mm} * 1.5$ $\mathrm{mm}$ is used to fabricate the prototype.

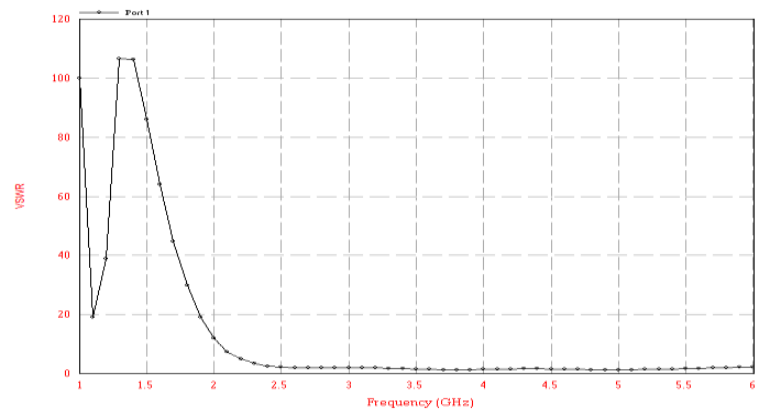

Figure 5. Simulated values of VSWR vs. Frequency

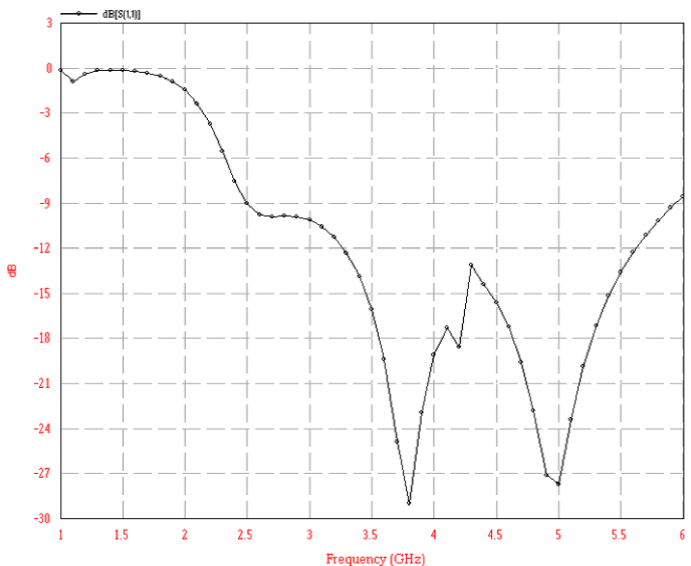

Figure 4. Simulated values of S11 vs. Frequency

The return loss variations with respect to the Frequency are represented in Fig. 5 which shows an enhanced impedance bandwidth of $63.64 \%$ in range from $3 \mathrm{GHz}$ to $5.8 \mathrm{GHz}$. The two resonances occur at frequency $3.8 \mathrm{GHz}$ and $5 \mathrm{GHz}$. The variations in VSWR with respect to the Frequency are shown in Fig.5. The antenna VSWR is found VSWR is found to be 1.073 and 1.085 at two resonance frequency $3.8 \mathrm{GHz}$ and 5 $\mathrm{GHz}$ which confirms low power reflection and enhance antenna performance. The directivity defines the maximum directional gain of an antenna and is found up to $5 \mathrm{dBi}$ in the operating range as shown in fig.6.
Directivity Vs. Frequency

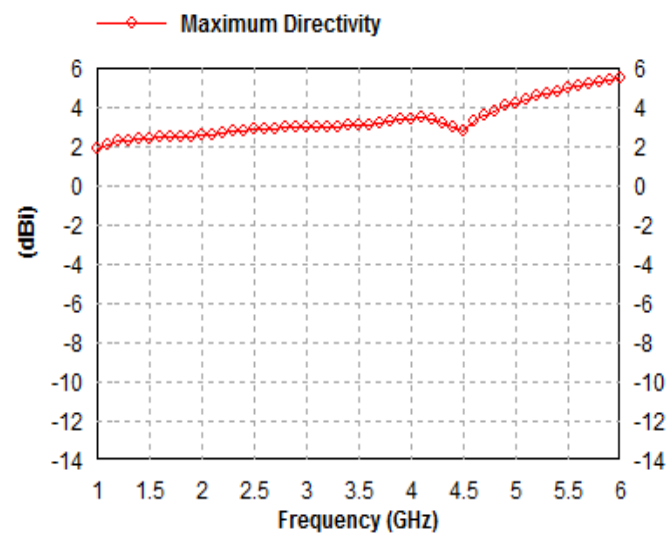

Figure 6. Simulated values of Directivity vs. Frequency

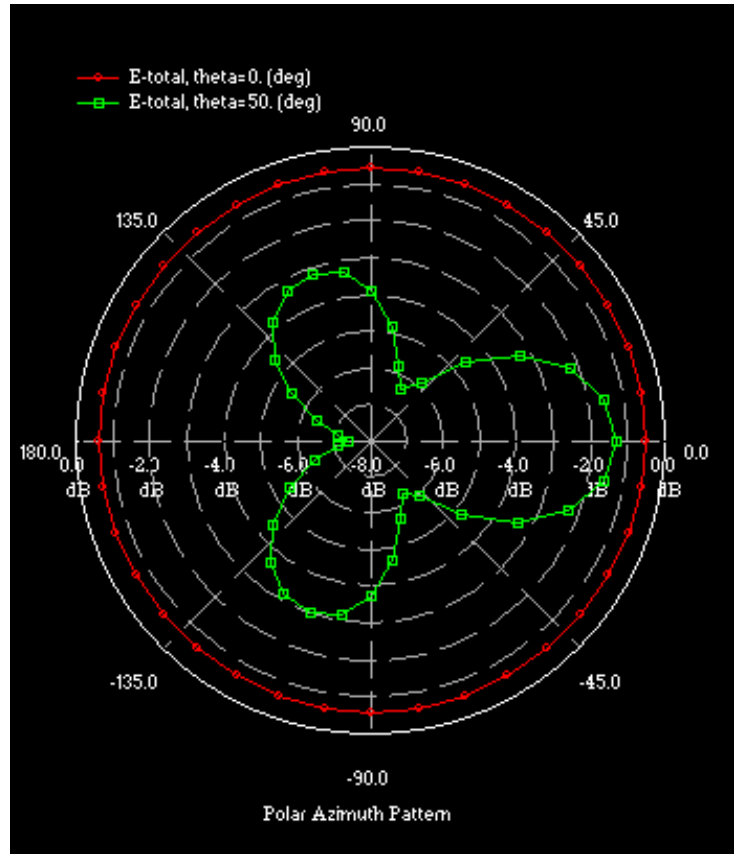

Figure 7. Radiation pattern of the proposed structure at $3.8 \mathrm{GHZ}$

The Radiation pattern for the designed structure at two resonances $3.8 \mathrm{GHz}$ and $5 \mathrm{GHz}$ are shown in fig.7 and fig. 8 respectively. The maximum antenna efficiency and radiating efficiency for proposed structure is found to be $84 \%$ and $95 \%$ respectively as shown in fig.9. 


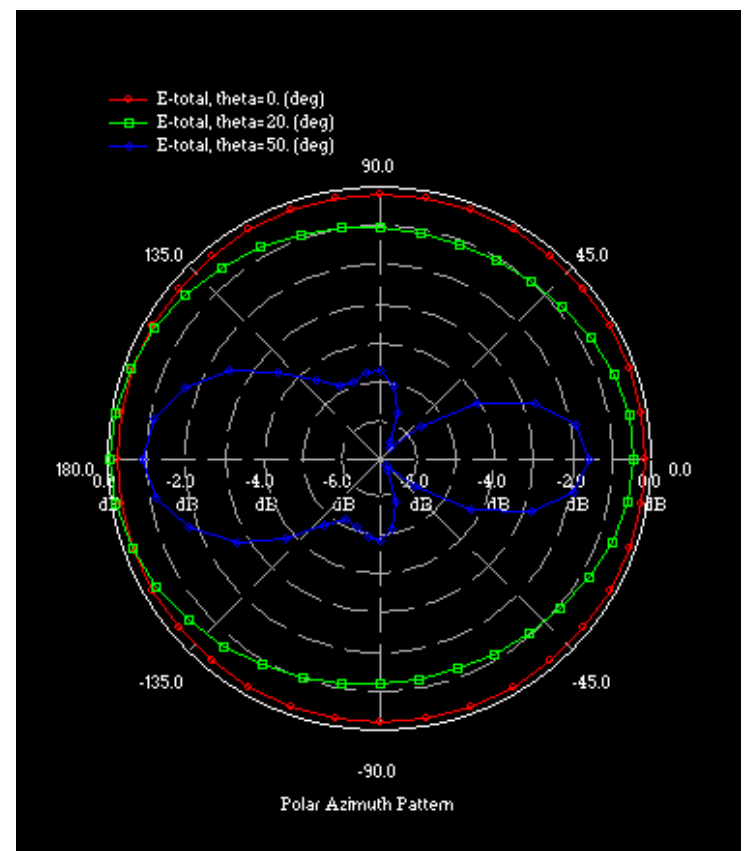

Figure 8. Radiation pattern of the proposed structure at 5 GHZ

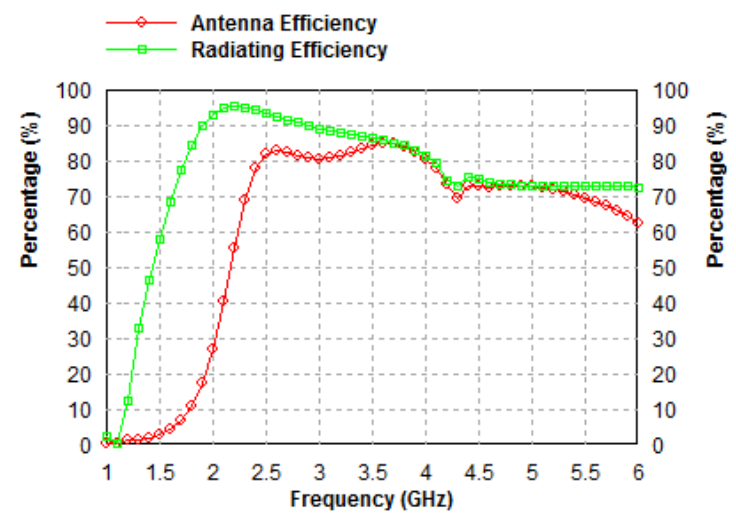

Figure 9. Simulated values of Efficiency vs. Frequency

\section{CONCLUSION}

The Microstrip-line-fed antenna with meandered ground plane and four truncated corners is designed. An impedance bandwidth of $63.64 \%$ in range from $3 \mathrm{GHz}$ to $5.8 \mathrm{GHz}$ has been achieved. The two resonances occur at frequency 3.8 $\mathrm{GHz}$ and $5 \mathrm{GHz}$ which covers $\mathrm{S}$ band and $\mathrm{C}$ band partially. The directivity of $5 \mathrm{dBi}$ is achieved in impedance bandwidth VSWR is found to be 1.073 and 1.085 at two resonance frequency $3.8 \mathrm{GHz}$ and $5 \mathrm{GHz}$. Thus proposed structure is suitable for "S" band and "C" band applications.

\section{REFERENCES}

[1] Garg R, Bhartia P, Bahl I, IttipiboonA.Microstrip antenna design handbook Artech House Inc.Norwood: 2001,ISBN 0-89006-513-6.

[2] Mukesh $\mathrm{Ku}$ Khandelwal, SantanuDwari, Kanaujia BK,Sachin Kumar, "Design and Analysis of Microstrip Patch Antenna With Enhanced for $\mathrm{Ku}$ Band Applications", ELSEVIER, AEUE-51203.

[3] Guha D. Biswas M, Antar YMM. "Microstrip Patch Antenna with Defected Ground Structure for Cross Polarization Suppression". IEEE ANTENNAS AND WIRELESS PROPAGATION LETTERS, VOL. 4,2005.

[4] Gautam AK, Kanuajia BK. A novel dual-band asymmetric slit with defected ground structure for circular polarization operation. Microv Opt TechnolLett 2013;55;1198-201.

[5] Jen-Yea Jan and Jia-Wei Su, "Bandwidth Enhancement of a Printed Wide-Slot Antenna with a Rotated Slot". IEEE TRANSACTIONS ON ANTENNAS AND PROPAGATION, VOL. 53, NO. 6, JUNE 2005.

[6] D. Guha, Y.M.M. Antar, J.Y. Siddiqui and M. Biswas, "Resonant resistance of probe- and microstrip-line-fed circular microstrip patches", IEEE TRANS ANTENNAS PROPAG., VOL. 152, NO. 6, DECEMBER 2005.

[7] D. M. Pozar, "Microwave Engineering," John Wieley\& Sons, ed. 2nd 1998. 